\title{
Burnout Syndrome (BS) among Emergency Medical Workers
}

\section{Nataliya Petrova*, Michail Duben, Sarkis Pogosyan and Vladimir Bratslavsky}

First Saint - Petersburg State Medical University, I.P. Pavlov, Russia

*Corresponding Author: Nataliya Petrova, First Saint - Petersburg State Medical University, I.P. Pavlov, Russia.
Received: July 22, 2020

Published: August 12, 2020

(C) All rights are reserved by Nataliya

Petrova., et al.

\begin{abstract}
The doctors and nurses belong to "person-person" professions. The features of these professions are: high responsibility, a large number of contacts with people, including the people with negative emotions. So they have the high risk of emotional stress. The work in emergency services is the work in difficult and even extreme situations with a high level of response, consequences for life and health. So this medical staff have a real risk of BS with its negative influence to health. In this article the results of BS study among emergency medical workers are presented. It was used a three-factor model of K. Maslach and S. Jackson (in the adaptation of N.E. Vodopianova): the level of emotional exhaustion, depersonalization, reduction of professional achievements were analyzed. The study involved 125 employees. The distribution according to the degree of emotional exhaustion was as follows: $10.8 \%$ of the respondents had a low degree, $16.2 \%$ had an average degree, $32.4 \%$ had a high degree and $40.6 \%$ had an extremely high degree of emotional exhaustion. The distribution by the degree of depersonalization was as follows: $5.4 \%$ of the respondents had a medium degree, $10.8 \%$ had a high degree, $83.8 \%$ had an extremely high degree. The distribution by the degree of depersonalization was as follows: $62.2 \%$ of the respondents had a low degree, $32.4 \%$ - an average degree and 5.4\% of employees had a high degree. The distribution of emotional burnout in total was as follows: $2.7 \%$ of respondents had a low degree, $8.1 \%$ had an average degree, $37.8 \%$ had a high degree, and $51.4 \%$ of respondents had an extremely high degree of emotional burnout. There are differences between some groups of respondents. The necessity of measures for the prevention of the syndrome among doctors has been proved.
\end{abstract}

Keywords: Burnout Syndrome; Medical Workers; Doctors' and Nursing' Health

\section{Introduction}

The health of medical workers is an important condition for their quality and effective work. It is known that in the process of professional activity, physicians and nurses are faced with a large number of adverse factors, one of which is a high level of psychological stress. Constant stress and high loads can lead to the development of burnout syndrome (BS) [1]. The World Health Organization characterizes burnout syndrome as physical, emotional or motivational exhaustion, with low level work productivity, fatigue, insomnia, and increased susceptibility to diseases. In ICD-
10 , burnout syndrome is considered under rubric Z73 - problems associated with the difficulties of maintaining a normal lifestyle [2].

\section{Related work}

The BS problem became the subject of scientific research in the 70s of the last century. First it was described by American psychologist Herbert Freidenberg. K. Maslach described it in more details. Later the term of BS became very popular [3]. In 1982 Maslach, Pelman and Hartman described three components of BS (three-factor model): 
- Emotional exhaustion (a feeling of emptiness, a decrease in emotional tone, loss of interest in work and communication)

- Depersonalization (indifferent and even negative attitude towards people, impersonal and formal contacts with people, lack of empathy, internal irritation, labeling)

- $\quad$ Reduction of professional achievements (low labor productivity and lack of motivation, leading to unsatisfactory results, negativism and lower self-esteem) [4].

Based on this model, K. Maslach and S. Jackson created a test for the diagnosis of burnout "MBI".

The representatives of social professions including medical workers, are most likely to BS, because they belong to "personperson" professions [5]. The features of these professions are: high responsibility, the risk of emotional stress because of a large number of contacts with people, including the people with negative emotions, the work in difficult and even extreme situations that require a quick response, serious consequences for life and health. As a result, physicians and nurses can feel the internal emotional emptiness and psychophysical stress [6].

There are various approaches to the analysis of BS, and although there is no consensus on its structure and the possibilities of prevention, all scientists agree that it can cause depression, which lead to addictions, medical errors, personality deformation and motivate for leaving the profession. Therefore, this problem requires additional study. Adequate corrective and preventive measures can prevent the developing of BS [7]. These measures will be more effective when they are based on a scientific analysis and take into account the individual characteristics of work. Although the occurrence of the syndrome is individually determined by the emotional-motivational sphere, but it also depends on social factors and the conditions of professional activity [8]. Therefore, the investigation of BS among different categories of medical workers is an actual task.

\section{Objectives of the Study}

The aim of the study was to identify the prevalence of BS among different categories of emergency medical care employees and the differences in the severity of emotional exhaustion among people of different sexes, ages, marital status, with and without chronic diseases.

\section{Materials and Methods}

In order to identify BS, the Maslach Burnout Inventory (MBI) technique was chosen, developed on the basis of a three-factor model of K. Maslach and S. Jackson (in the adaptation of N.E. Vodopianova). The test consists of 22 questions on which it is possible to calculate the values of three subscales: emotional exhaustion, depersonalization, reduction of professional achievements. Emotional exhaustion reflects the severity of the emotional state associated with work activities. According to this subscale, the respondent can score up to 54 points ( 6 - 16 points - low level, 17 - 25 - average level, 26 - 34 - high level, more than 34 points indicate the presence of an extremely high level of emotional exhaustion). Depersonalization reflects the level of relationships with colleagues. It can be manifested by emotional detachment and indifference, the formal performance of official duties. At the behavioral level, it manifests itself in arrogant behavior, the use of professional slang and humor. As much as possible on this subscale, it is possible to score up to 30 points ( 1 - 4 points - a low level of depersonalization, 5 - 10 points - an average level, 11 - 13 points - a high level, more than 14 points - an extremely high level of depersonalization). Reduction of professional achievements is a subscale, reflecting the degree of satisfaction of an own health. This subscale has the opposite character, the more points reflect the lower level of reduction of professional achievements. The maximum number of points for this subscale is 48 (48-36 points - low level, 35-28 points - medium level, 27 - 22 points - high level, less than 21 points indicates an extremely high level of reduction of professional achievements). After passing the test, the total score for each sub-factor is calculated. Evaluation can be carried out for both a specific indicator and an integrated burn-out indicator. To calculate the integral indicator, it is necessary to add scale estimates of three indicators and correlate with test standards ( 3 - 4 points - low degree of emotional burnout, 5 - 6 points - medium degree, 7 - 9 points - high degree, 10 points or more - extremely high degree of emotional burnout).

The study involved 125 employees (doctors and nurses) who take part in emergency medical care (ambulance, emergency room, anesthesiology and intensive care unit). There most of the respondents are the women (78.4\%). 28.9\% of respondents were younger than 30 years old, $24.3 \%$ were aged 30 - 39, 24.3\% - 40 - 49, 21.6\% were aged 50 years and older. The distribution by marital status was as follows: $75.7 \%$ of respondents were registered in a mar- 
riage, $2.7 \%$ - in an unregistered marriage, $21.6 \%$ of the respondents were not married. The distribution according to the length of service was the next: $64.9 \%$ of the respondents had a length of service of more than 10 years, $18.9 \%$ had a length of service of 5 - 10 years, $16.2 \%$ had a length of service of up to 5 years. Almost half $(45.9 \%)$ of the respondents had chronic diseases. The percentage of people with chronic diseases increases from $27.2 \%$ (in the age under 30 ) to $100.0 \%$ (in the age 50 and older). This article describes predominantly the results of the analysis of the first of BS phases.

\section{Results and Discussion}

The emotional exhaustion is one of the manifestations of emotional burnout. The distribution according to the degree of emotional exhaustion was as follows: $10.8 \%$ of the respondents had a low degree, $16.2 \%$ had an average degree, $32.4 \%$ had a high degree and $40.6 \%$ had an extremely high degree of emotional exhaustion. The percentage of those who had an extremely high degree of emotional exhaustion was maximum in the age group 30 - 39 and 40 - 49 years old (55.6\%) (the degree of emotional exhaustion among respondents of different ages was shown in table 1).

\begin{tabular}{|l|c|c|c|c|c|}
\hline \multirow{2}{*}{ Age } & \multicolumn{5}{|c|}{ Emotional exhaustion } \\
\cline { 2 - 6 } & $\begin{array}{c}\text { Low } \\
\text { degree }\end{array}$ & $\begin{array}{c}\text { Medium } \\
\text { degree }\end{array}$ & $\begin{array}{c}\text { High } \\
\text { degree }\end{array}$ & $\begin{array}{c}\text { Extremely } \\
\text { high degree }\end{array}$ & Total \\
\hline Up to 30 & 27,3 & 9,1 & 45,5 & 18,1 & 100,0 \\
\hline $30-39$ & 0 & 11,1 & 33,3 & 55,6 & 100,0 \\
\hline $40-49$ & 11,1 & 11,1 & 22,2 & 55,6 & 100,0 \\
\hline $\begin{array}{l}50 \text { and } \\
\text { more }\end{array}$ & 0 & 37,5 & 25,0 & 37,5 & 100,0 \\
\hline All ages & 10,8 & 16,2 & 32,4 & 40,6 & 100,0 \\
\hline
\end{tabular}

Table 1: Distribution of respondents of different ages by the degree of emotional exhaustion, $\%$.

There was revealed a difference in the severity of this phase among people with different marital status. The percentage of people with low degree of emotional exhaustion was higher among unmarried people compared with those in a registered marriage (25.0\% and $7.1 \%$, respectively). The average degree was presented only among married respondents (21.4\%) (the degree of emotional exhaustion among respondents of different marital status was shown in table 2).

\begin{tabular}{|l|c|c|c|c|c|}
\hline \multirow{2}{*}{$\begin{array}{l}\text { Marital } \\
\text { status }\end{array}$} & \multicolumn{5}{|c|}{ Emotional exhaustion } \\
\cline { 2 - 6 } & $\begin{array}{c}\text { Lew } \\
\text { degree }\end{array}$ & $\begin{array}{c}\text { Me- } \\
\text { dium } \\
\text { degree }\end{array}$ & $\begin{array}{c}\text { High } \\
\text { degree }\end{array}$ & $\begin{array}{c}\text { Ex- } \\
\text { tremely } \\
\text { high } \\
\text { degree }\end{array}$ & Total \\
\hline $\begin{array}{l}\text { Registered } \\
\text { marriage }\end{array}$ & 7,1 & 21,4 & 28,6 & 42,9 & 100,0 \\
\hline $\begin{array}{l}\text { Unregistered } \\
\text { marriage }\end{array}$ & 0 & 0 & 100,0 & 0 & 100,0 \\
\hline Single & 25,0 & 0 & 37,5 & 37,5 & 100,0 \\
\hline Total & 10,8 & 16,2 & 32,4 & 40,6 & 100,0 \\
\hline
\end{tabular}

Table 2: Distribution of respondents with different marital status according to the degree of emotional exhaustion, \%.

The severity of emotional exhaustion among women was higher than among men. Thus, the percentage of people with an extremely high degree of exhaustion, respectively, amounted to $44.9 \%$ and $25,0 \%$ (the degree of emotional exhaustion among men and women was shown in table 3).

\begin{tabular}{|l|c|c|c|c|c|}
\hline \multirow{2}{*}{ Gender } & \multicolumn{5}{|c|}{ Emotional exhaustion } \\
\cline { 2 - 6 } & $\begin{array}{c}\text { Low } \\
\text { degree }\end{array}$ & $\begin{array}{c}\text { Medium } \\
\text { degree }\end{array}$ & $\begin{array}{c}\text { High } \\
\text { degree }\end{array}$ & $\begin{array}{c}\text { Extremely } \\
\text { high de- } \\
\text { gree }\end{array}$ & Total \\
\hline Male & 12,5 & 25,0 & 37,5 & 25,0 & 100,0 \\
\hline Female & 10,3 & 13,8 & 31,0 & 44,9 & 100,0 \\
\hline Both sexes & 10,8 & 16,2 & 32,4 & 40,6 & 100,0 \\
\hline
\end{tabular}

Table 3: Distribution of respondents of different sexes by the degree of emotional exhaustion, \%.

Among people with chronic diseases, the proportion of those who had a high and extremely high degree of emotional exhaustion was higher (76.5\%), compared with those who did not have these diseases $(70.0 \%)$ (the degree of emotional exhaustion among respondents who have and don't have chronic diseases was shown in table 4).

There are some differences in the severity of emotional exhaustion among doctors and nurses. In particular, among the doctors there were no respondents with a low degree of its severity. The degree of emotional exhaustion among doctors and nurses was shown in table 5). 


\begin{tabular}{|l|c|c|c|c|c|}
\hline \multirow{2}{*}{$\begin{array}{l}\text { Chronic } \\
\text { diseases }\end{array}$} & $\begin{array}{c}\text { Low } \\
\text { degree }\end{array}$ & $\begin{array}{c}\text { Medium } \\
\text { degree }\end{array}$ & $\begin{array}{c}\text { High } \\
\text { degree }\end{array}$ & $\begin{array}{c}\text { Extremely } \\
\text { high } \\
\text { degree }\end{array}$ & Total \\
\hline There are & 5,9 & 17,6 & 41,2 & 35,3 & 100,0 \\
\hline None & 15,0 & 15,0 & 25,0 & 45,0 & 100,0 \\
\hline Total & 10,8 & 16,2 & 32,4 & 40,6 & 100,0 \\
\hline
\end{tabular}

Table 4: Distribution of respondents with and without chronic diseases according to the degree of emotional exhaustion, $\%$.

\begin{tabular}{|l|c|c|c|c|c|}
\hline \multirow{2}{*}{ Position } & \multicolumn{5}{|c|}{ Emotional exhaustion } \\
\cline { 2 - 6 } & $\begin{array}{c}\text { Low } \\
\text { degree }\end{array}$ & $\begin{array}{c}\text { Medium } \\
\text { degree }\end{array}$ & $\begin{array}{c}\text { High } \\
\text { degree }\end{array}$ & $\begin{array}{c}\text { Extremely } \\
\text { high } \\
\text { degree }\end{array}$ & Total \\
\hline Doctors & 0 & 20,0 & 40,0 & 40,0 & 100,0 \\
\hline Nurses & 12,5 & 15,6 & 31,2 & 40,7 & 100,0 \\
\hline Total & 10,8 & 16,2 & 32,4 & 40,6 & 100,0 \\
\hline
\end{tabular}

Table 5: Distribution of doctors and nurses by the degree of emotional exhaustion, \%.

The second manifestation of emotional burnout is depersonalization. The distribution by the degree of depersonalization was as follows: $5.4 \%$ of the respondents had a medium degree, $10.8 \%$ had a high degree, $83.8 \%$ had an extremely high degree.

The reduction of professional achievements is another manifestation of burnout. The distribution by the degree of depersonalization was as follows: $62.2 \%$ of the respondents had a low degree, $32.4 \%$ - an average degree and $5.4 \%$ of employees had a high degree.

The distribution of emotional burnout in total was as follows: $2.7 \%$ of respondents had a low degree, $8.1 \%$ had an average degree, $37.8 \%$ had a high degree, and $51.4 \%$ of respondents had an extremely high degree of emotional burnout.

\section{Conclusion}

The study proved the urgency of the problem BS among emergency medical personnel. $73 \%$ of them have a high and extremely high degree of emotional exhaustion; $94.6 \%$ - of depersonalization and $5.4 \%$ - of reduction of professional achievements. The severity of symptoms differed among people of different sex, age, marital status, with the presence and absence of chronic diseases, among doctors and nurses. This requires the development and realization of a system measures aimed at the prevention and treatment of symptoms of burnout syndrome.

\section{Conflict of Interests}

The authors have no conflict of interests.

\section{Bibliography}

1. MA Kovalchuk. "Burnout syndrome in social professions and methods of its prevention". Yaroslavl: Publishing House of FSBEI of HE Yaroslavl State Agricultural Academy (2017): 128.

2. TA Rovova and IA Romanova. "Psychological aspects of emotional burnout of employees”. Krasnodar: Kuban state University (2015): 120 .

3. M Yu Lazareva and KO Nazarova. "How to recognize burnout syndrome and correct the situation before it is too late". Head Nurse 8(2019):56-65.

4. C Maslach. Burnout. The cost of caring, CA.: Los Altos: Malor books (2015): 276

5. LS Chutko and NV Kozina. Burnout Syndrome. Clinical and psychological aspects, 3rd ed., M: MEDpress-inform (2015): 256.

6. GA Tkachenko and VA Agafonov. "Professional burnout at doctors and nurses of cancer clinics". M: FSBEI IN RNIMU N.I. Pirogova (2018): 48.

7. Yu Veselova and PA Veselova. "Factors of professional-emotional burnout among medical workers in dentistry". Nurse 9 (2017): 75-79.

8. TM Skovholt and M Trotter-Mathison. "The resilient practitioner: burnout and compassion fatigue prevention and self care strategies for the helping professions". London and New York: Taylor and Francis Group (2016): 304.

\section{Assets from publication with us}

- Prompt Acknowledgement after receiving the article

- Thorough Double blinded peer review

- Rapid Publication

- Issue of Publication Certificate

- High visibility of your Published work

Website: www.actascientific.com/

Submit Article: www.actascientific.com/submission.php Email us: editor@actascientific.com

Contact us: +919182824667 